\title{
XV Festival Internacional de Música Contemporánea
}

\author{
por \\ Fernanda Ortega Sáenz \\ Departamento de Música \\ Universidad Metropolitana de Ciencias de la Educación \\ lfortega@uc.cl
}

Entre el lunes 12 y el viernes 16 de enero de 2015 se desarrolló el XV Festival Internacional de Música Contemporánea que organiza el Departamento de Música y Sonología de la Facultad de Artes de la Universidad de Chile (DMUS).

Esta decimoquinta versión fue presentada por el compositor Eduardo Cáceres Romero, director artístico del Festival, como una "fiesta de la música contemporánea" y una "invitación a oír las músicas contemporáneas" de todo el mundo. La Decana de la Facultad de Artes, profesora Clara Luz Cárdenas Squella, realizó un saludo protocolar. El compositor Fernando Carrasco Pantoja, Director del Departamento de Música y Sonología, señaló que esta actividad es parte de las labores del Departamento que obedecen al mandato legal del Estado de Chile a esta Universidad. Vinculó al festival con la reforma educacional en curso, en el sentido de hacer un llamado "para que lo nuevo advenga". Las anteriores frases hicieron presagiar una semana de descubrimientos estimulantes e inusitados que veremos si se reflejaron en la música.

El Homenaje, con el que tradicionalmente parte el festival, recayó en el compositor León Schidlowsky, Premio Nacional de Artes Musicales 2014 y estuvo a cargo del Dr. Luis Merino Montero. A continuación el profesor Wilson Padilla interpretó Isla Negra (1959) para flauta. Como ya es habitual, la música recién se inició más de cuarenta minutos después de la hora programada. En total se presentaron en el festival 31 obras de cámara y dos obras sinfónicas. Nueve obras fueron estrenos absolutos y 11 obras fueron estrenos en Chile. Dieciséis obras correspondieron a compositores nacionales, 11 a creadores de otros países de América Latina, mientras que cuatro obras provinieron de Europa y dos obras de los Estados Unidos.

Resulta de interés cotejar estas cifras con la afirmación acerca de este evento como un "festival americanista”, reiterada varias veces durante la semana. ¿Es americanista por la cantidad de obras del sur del continente? ¿O por situarse en una determinada posición estético-musical, geográfico-política o económica? ¿Es americanista por opción o por obligación, en cuanto a los recursos con los que contó esta versión? Esto último hace recordar las siguientes palabras del compositor Gustavo Becerra Schmidt en cuanto a que son nuestras diferencias las que nos unen: "lo más nacional [o latinoamericano en este caso] que tenemos son nuestros problemas y nuestras ideas. Valga esto también para el arte y, especialmente, para la música"1. En lo que respecta al americanismo, conviene evocar también las palabras de Gabriel Castillo Fadic, para quien la posible unidad de las culturas latinoamericanas "es más bien por el lado de sus impedimentos que hay que buscarla: pobreza, militarismo, endeudamiento, dependencia económica, son términos que no hacen una identidad pero que marcan una comunidad

1 Becerra 1972: 9. 
de destinos" 2 . Sin afán de darle una interpretación negativa se podría discutir in extenso el término para darle algo más de espesor a la idea de un festival americanista en lo musical.

Este año predominaron las obras para instrumento solista, las que ascendieron a 16 de un total de 31 obras. Seis de estas obras fueron escritas para diversas variantes de cuarteto. Disminuyeron las obras sinfónicas así como las de ensamble, entre los que se destacaron las agrupaciones estables que se habían presentado en versiones anteriores. Desde el DMUS, el ensamble Compañía de Música Contemporánea dirigido por Carlos Valenzuela mostró nuevamente un buen nivel interpretativo con Esto ya lo toqué mañana (2014) de Ramón Gorigoitía, una enérgica obra que motivó a la audiencia por su sentido del humor, teatralidad y una muy buena presentación de Miguel Villafruela. Con una mezcla de lenguaje contemporáneo e improvisación de jazz, la partitura perdió algo de su novedad al ser comparada con la obra de Brouwer que se tocó posteriormente. El ensamble hizo muestra de la seriedad de su trabajo al cerrar el día viernes 16 de enero esta edición del festival con la interpretación del Pierrot Lunaire (1912) de Arnold Schoenberg, una obra que presentó durante 2014, pero que en esta ocasión figuró a continuación de la Orquesta Sinfónica de Chile (OSCh) en el Teatro de la Universidad de Chile. Al no despejarse el escenario para la presentación del ensamble, este tuvo que acomodarse o incomodarse entre las sillas y atriles de la orquesta, cuando en realidad la labor de clausura debió haberla realizado la OSCh. Los miembros de Compañía presentaron además Melencolia (a3) (2013) de Mauricio De Bonis, compositor brasileño invitado. Obra de estética europeo-germana, con el piano activo y rítmico en contrapunto a melodías delicadas del violín y violonchelo, requirió algo más de trabajo de conjunto para que fuera correctamente apreciada.

Ludus Metallicus (1972), del cubano Leo Brouwer, figuró entre las obras más destacadas y propositivas del festival. Fue excelentemente interpretada por el Cuarteto de Saxofones Oriente, conjunto que interpretó además otra obra en el festival. De escritura gráfica, notación aleatoria e instrucciones para la sección performática, deja gran parte de la responsabilidad a los intérpretes que al final abandonan la escena tocando sus instrumentos. Menos certero estuvo esta vez el Cuarteto Surkos, por un reciente cambió de conformación, en la interpretación de Girale (2011) de Miguel Farías. En el Cuarteto de cuerdas $\mathrm{N}^{\circ} 1$ que permanecía sin estrenar, vimos cómo este compositor experimentaba con sonoridades y diversas técnicas instrumentales, con una intención de lenguaje contemporáneo.

Hubo dos buenas iniciativas en el festival. La Orquesta de Flautas Illawara, ensamble de la Universidad de Chile, es un buen recurso didáctico para los estudiantes. Bajo la dirección de Wilson Padilla presentó Illawara sube por el canto del agua (2013) de Edgardo Cantón. Obra minimalista, pudo sacar mayor provecho de la variedad de registros del grupo instrumental, los que más bien se fueron adicionando en líneas melódicas simples. Por su parte el Cuarteto Resonancia Femenina de Valparaíso con Clarice (2014) de Valeria Valle, tuvo un buen desempeño. De una interesante escritura, podría explorar dinámicas más suaves y tal vez extender la obra, algo breve, para manejar más recursos compositivos.

Disminuyeron las partituras vocales puesto que figuraron solo cuatro obras de cámara con voz solista. La obra de referencia fue Pierrot Lunaire. Entre las nacionales se destacó las Canciones humanas (2013-14) de René Silva, un compositor que ha perfeccionado su oficio. Con textos del poeta chilote Manuel Zúñiga fueron bien acogidas. La primacía del acompañamiento la tuvo el piano. Por momentos el violín quedó relegado hasta llegar su turno para tomar relieve. Ciertos giros recordaron el repertorio chileno de décadas anteriores. Podría tal vez el compositor probar con sumergirse en otros lenguajes, explorando sonoridades y jugando más con texturas con lo que sin duda ganará en recursos. El joven compositor Joaquín Muñoz presentó 3 Antipoemas antimusicalizados (2014). Este concepto inspirado en Nicanor Parra no se vio reflejado en lo que la obra transmite. Requirió presentar palabras antes de la música, la que apareció por momentos como una suerte de tango de escritura simple. Bien lograda la voz, la obra tiene una atractiva intención musical que puede ser pulida mediante un mayor trabajo de texturas y de escritura instrumental. Para transmitir un aspecto irónico puede hacerlo todavía con mayor precisión y elaboración. La obra con voz Díptico (2013-14), de Hernán Ramírez, presentó un cierto desbalance entre la parte vocal y el sonido del conjunto, sobre textos de Gabriela Mistral y Nicanor Parra en melodías de intervalos amplios.

En cuanto a las nuevas tecnologías -consistente más bien en audios pregrabados y poca electrónica en tiempo real, sin inclusión de otros recursos-, hubo cinco obras con algún dispositivo electrónico, un número similar al de las últimas versiones del festival. Del ecuatoriano Mesías Maiguashca, sus Cinco

2 Castillo Fadic 2003: 20 
microgramas (2014), con novedosas afinaciones para la guitarra solista, técnicas extendidas y cajón peruano con la electrónica fue interesante, si bien no fue fácil de seguir para el público por lo extenso de algunas secciones, más aun considerando que fue programada al cierre del día inaugural. Blood Stream (2003), del mexicano Rodrigo Sigal, mostró poca relación entre la electrónica y lo que hizo la tuba. Se unieron mediante la respiración del tubista, reutilizada por la electrónica, con insistencia en los registros bajos. Bien lograda estuvo Alf Tua (2000) de uno de los invitados internacionales, el argentino Gonzalo Biffarella. Con pasajes que transmitían un cierto dramatismo y una electrónica granulada, ocupó bien el espacio en una adecuada relación con la flauta mediante sonidos eólicos y algunas técnicas extendidas. Solo el final fue un tanto abrupto. Mit Werk o el Tiempo transversal (2012) del chileno Andrés González, demostró un muy buen trabajo del solista Cesar Bernal, un contrabajista muy comprometido en la interpretación. El intercambio con la electrónica fue algo inorgánico, pero se desarrolló como una sucesión de secciones entre ambos que pudo haber tenido mayor continuidad o fluidez. Escrita durante sus estudios en Alemania, la obra mostró una búsqueda sonora y dinámica.

Entre los jóvenes que estudian en la Universidad de Chile, el compositor colombiano Alejandro Hernández presentó Causa y Efecto (2013-14), un trabajo cuidadoso y detallista. Buena mixtura de los cuatro instrumentos en una gestualidad constante, generó una sucesión de secciones rápidas y lentas que tendieron a un carácter de insinuante intensidad. Asimismo, Nicolás Cortés con Panorama (2014) para violonchelo y piano tocada con juvenil brío con el compositor al piano, podría brillar más con un trabajo de mejor profesionalismo de dicho instrumento. De escritura densa y pasajes de complejidad para la ejecución, estimuló a esperar futuros trabajos del creador.

Las dos obras elegidas por el Comité Seleccionador para ser interpretados por la OSCh el día de clausura son igualmente destacables. El sonido de la noche (2014) de Sebastián Molina tuvo una algo opaca versión de la orquesta. La obra no siguió una forma precisa, sino más bien se construyó en capas y bloques sonoros que se fueron sucediendo y contraponiendo. Después de una larga introducción colorística incrementa la actividad rítmica, pero sin decidirse finalmente por alguna dirección a seguir. Breves pausas marcaron nuevas secciones que crecen, decrecen y de esta forma desaparecen al final. Por su parte, Ignacio Salvo presentó Leyendas de los bosques (2013-14), basada en tres cuentos de la Europa medieval que se sucedieron sin pausa. Según señaló este joven compositor, la obra marcó el resultado final de su proceso como músico autodidacta, lo que se pudo apreciar en los recursos utilizados, un fruto probable de exhaustivas audiciones del repertorio orquestal universal. Algo fragmentada, lo que impidió construir un discurso más claro, utilizó un gran efectivo instrumental para buscar dramatismo expresivo en una ejecución de la OSCh que estuvo por momentos imprecisa. La incorporación de la voz de los músicos de orquesta al final fue algo gratuita en relación con el resto de la obra.

Entre algunas de las piezas solistas escuchamos cinco piezas de A Little Suite for Christmas (1980) del norteamericano George Crumb, en la cual Virna Osses realizó un excelente trabajo. Obra posterior a los Makrokosmos de los años setenta, se reconocen influencias de Messiaen, Debussy, Cowell, junto a las características técnicas extendidas de Crumb para el piano. Las Quattro pezzi per tromba (1956), una curiosa obra de Giacinto Scelsi de estilo inasible, resultaron un aporte al festival. Fue escrita pocos años antes de su etapa más emblemática caracterizada por la exploración exhaustiva de sonoridades en torno a una o pocas notas. Se trata de una suerte de estudios en los que abarcó desde el registro abierto de la trompeta hasta el extremo de la sordina con escritura floreada, una obra bien interpretada por Benjamín Vergara. Entre las invitadas internacionales estuvo la compositora argentina Marta Lambertini con L'alto veliero (2008). Para "flauta recitante" con texto en italiano, combinó el instrumento con la voz, apoyada por amplificación. Además de una sonoridad de añoranza ritual, melismática, utilizó bien el instrumento. Del fuego las resonancias (1992) del argentino Luis Naón, obra idiomática e interesante, fue bien tocada por Cristián Alvear, así como la obra de Fernando García Tres piezas breves (1995) para guitarra por parte de Luis Orlandini. Del recientemente fallecido Gerardo Gandini, sus Seis tientos para guitarra (1977) es una suerte de suite que con escritura puntillista y fragmentaria exigió la entrega del guitarrista Ricardo Cuadros, invitado de Colombia.

Como una novedad de esta versión, entre lunes y jueves de la semana se exhibieron videos de las anteriores ediciones del festival en una sala dispuesta durante todo el día especialmente para ello. $\mathrm{Al}$ parecer no tuvo la acogida esperada, pero es igualmente positivo saber que aquellos registros acumulados desde hace algunos años en la Mediateca del Departamento finalmente salieron a la luz. Se espera replicar esta iniciativa en las futuras versiones.

La siempre esperada participación de la Orquesta Sinfónica consistió esta vez en la interpretación de dos obras ya señaladas de jóvenes compositores bajo la dirección de Francisco Rettig. Insistiendo 
en que su inclusión es un importantísimo aporte, la orquesta no brilló como en las dos versiones anteriores en las que ha cerrado el festival. Apreciamos a la OSCh un tanto apagada, con una baja en su justeza y precisión en relación con otras presentaciones. Al parecer por razones de programación (¿o de presupuesto y compromiso?) quedamos inevitablemente con la sensación de haber perdido la oportunidad de escuchar alguna de las tantas obras orquestales contemporáneas que en nuestro país no han sido tocadas.

A modo de comentarios generales de esta versión, nuevamente hubo un muy buen trabajo del equipo de sala. Menos positiva resultó la baja notable de público. Esto deja planteada la pregunta acerca de si fue una señal de alarma del inicio de la curva descendente de la asistencia de público a este festival, como ha ocurrido con eventos de otras casas universitarias. Reflexiones sobre esta cuestión pueden ser innumerables, pero me arriesgo con un par de ellas. Están por un lado los problemas de financiamiento debidos a la dependencia de fondos concursables. Esto obligó a una cierta improvisación en la programación y organización previa. Hubo así menos obras de orquesta, de ensamble y más invitados locales, lo que pareció por momentos justificarse en la idea de dar a este festival un carácter latinoamericano ¿o latinoamericanista? En la dirección de un festival confluyen una serie de relaciones de intercambio simbólicas, en la que el Director Artístico, Eduardo Cáceres, ha sido el rostro visible. Por otro lado está un proceso que se advierte en las dos últimas versiones, en cuanto a la despersonalización del festival, lo que es un asunto para evaluar. La buena noticia finalmente fue la obtención de los fondos concursables del Consejo Nacional de la Cultura y las Artes (CNCA) para este festival 2015 y las dos próximas versiones.

En cuanto al año de composición, para esta versión la obra más antigua fue Pierrot Lunaire de Schoenberg de 1912, luego Boulez de 1945 y Cage, Scelsi y Schidlowsky en los cincuenta. Siguieron apenas cuatro obras desde los años sesenta a los ochenta, tres en los noventa y 21 obras creadas en el siglo XXI, entre las cuales ocho fueron compuestas íntegramente en 2014. A partir de esto y haciendo un poco de memoria, es posible ver que en las últimas versiones del festival varias de las partituras más antiguas -los clásicos contemporáneos- son las más importantes y recordadas. Claro que estas ya han sobrepasado la selección natural del tiempo. Aun así, muchas veces han resultado ser las más novedosas e incluso sorpresivas. Ejemplo de esto es lo que provocó Water Music (1952) de John Cage, para piano y objetos, que pudo resultar incomprensible para parte del público que no supo cómo reaccionar. El exceso de silencios y la aparente "no interpretación" de la intérprete, que en palabras de espectadores "no tocó nada", generó comentarios, preguntas, risas. Y siguiendo esta idea de lo sorpresivo con un ejemplo más reciente, se produjo igualmente confusión con TransFormantes IV (1998), obra alternada para ensamble y clarinete del brasileño Flo Menezes. De estas obras se tocaron cuatro formantes de un total de 13, que insistieron en los registros agudos bien ejecutados en el clarinete por Cecilia Arce. El público se vio desconcertado frente a esta obra presentada de forma discontinua, en la que la respuesta repetida y más evidente fue la risa vana.

Lo anterior no quiere decir que deba existir una posibilidad única de reacción o apreciación musical respecto del repertorio actual, más aun siendo este un festival universitario abierto a todos, sino más bien apreciar cómo las músicas llamadas contemporáneas pueden restringirse en espacios de festivales institucionales a un patrón a veces reducido de posibilidades musicales y estéticas. ¿Es posible establecer una idea certera de cuándo una obra es novedosa, avanzada, atrevida, exploradora? ¿Qué tipo de obras espera oír el público? Difícil tarea llegar a acuerdo. ¿Cuáles obras marcan mayores influencias en los compositores nacionales? Y por sobre todo, ¿Qué buscan o proponen todas aquellas obras chilenas del siglo XXI? Las preguntas quedan abiertas. Tal vez y en parte estén a la siga de aquel mencionado americanismo.

\section{BIBLIOGRAFÍA}

Becerra Schmidt, Gustavo

1972 “Becerra 1972”, RMCh, XXVI/119-120 (julio-diciembre), pp. 8-18.

Castillo Didier, Gabriel

2003 Las estéticas nocturnas: ensayo republicano y representación cultural en Chile e Iberoamérica. Santiago: Colección Aisthesis 30 años, Pontificia Universidad Católica de Chile. 